\title{
Políticas públicas dirigidas a la Economía Social y Solidaria. Tensiones, alcances y desafíos en la experiencia de San Martín (Argentina, 2016-2017)
}

Public policies aimed at the Social and Solidarity-based Economy. Tensions, scopes and challenges in the San Martin experience (Argentina, 2016-2017)

\author{
Ariel GARCÍA \\ Investigador Adjunto (CEUR-CONICET)
}

Fernando FontaneT

Ayudante de 1ra (Facultad de Ciencias Sociales-UBA)

DOI: $10.1387 /$ reves.20519

Fecha de entrada: 14/01/2018

Fecha de aceptación: 01/03/2018

Sumario: Introducción.-Políticas públicas y agenda pública en la ESS.-

Asociativismo, reciprocidad y solidaridad en la ESS. - La experiencia del

Municipio de San Martín.-Reflexiones finales.— Bibliografía.

\section{Resumen:}

Esta investigación se interroga por las formas efectivas que adquiere el asociativismo en las experiencias de economía social y solidaria (ESS) registradas en la Municipalidad de San Martín (Argentina) para el bienio 2016-2017. Desde un enfoque de triangulación metodológica, el trabajo se propone: a) analizar las tensiones entre los ideales de asociativismo propugnado desde las experiencias de ESS y las formas de proceder que se registran en los participantes de la misma; b) describir las formas de intervención estatal en las experiencias asociativas seleccionadas, considerando específicamente fuentes y modalidades de asistencia técnica (financiamiento y de capacitación). La investigación halla una marcada dependencia de los trabajadores asociados a dispositivos del financiamiento estatal. Esta dependencia impide un efectivo esquema emancipatorio, aspecto que se vuelve estructural debido a la carencia de espacios alternativos y/o específicos de comercialización y de financiamiento. 


\title{
Palabras clave:
}

Políticas públicas, economía social y solidaria, asociativismo, solidaridad.

\begin{abstract}
:
This paper reflects about effective forms that the associativism acquires in the experiences of social and solidarity economy (SSE) registered in the Municipality of San Martin (Argentina) for the lapse 2016-2017. From a methodological triangulation approach, the work is proposed: a) to analyze the tensions between the ideals of associativism advocated from the ESS experiences and the ways of proceeding that are registered in the participants of the same; b) describe the forms of state intervention in the selected associative experiences, specifically considering sources and modalities of technical assistance (financing and training). The research finds a marked dependence on workers associated with state financing devices. This dependence inhibits an effective emancipatory scheme, an aspect that becomes structural due to the lack of alternative and / or specific spaces for commercialization and financing.
\end{abstract}

\section{Keywords:}

Public policy, social and solidarity Economy, asociativism, solidarity.

\section{Claves Econlit:}

D02-D63-E26-F61-H72-J54.

\section{Introducción ${ }^{1}$}

Esta investigación surge de inquietudes en torno a las formas efectivas que adquiere el asociativismo en las experiencias de economía social y solidaria (ESS) que se enmarcan en políticas públicas desarrolladas entre 2003 y 2017 en Argentina. ${ }^{2}$ Usualmente, se recurre al análisis de iniciativas de

${ }^{1}$ Esta investigación se enmarca en el Proyecto UBA-Investigación en grupos (2017) de la Cátedra de Economía Política (TS-FSOC-UBA): Experiencias productivas asociativas y métodos para la investigación desde una perspectiva estructuralista. Cátedra de Economía Política, Facultad de Ciencias Sociales. Se ha realizado a partir de encuentros mensuales efectuados en el Centro de Estudios Urbanos y Regionales (CEUR-CONICET) e incluyó trabajo de campo en los ámbitos donde se desarrollan los casos seleccionados.

2 El lapso 2003-2017 se puede subdividir en dos etapas diferenciadas: a) 2003-2015, caracterizadas por la sucesión de tres gobiernos nacionales que desplegaron políticas públicas redistributivas enfocadas en la generación de empleo y la sustitución de importaciones; b) desde 2015, la asunción de un gobierno que impulsa políticas públicas de corte neoclásico, asentadas en la distribución regresiva del ingreso nacional. 
este tipo bajo la premisa de que el asociativismo es una conducta aceptada y practicada de hecho por sus integrantes. Sin embargo, la experiencia práctica dista de ajustarse a los preceptos teóricos. Desde un enfoque de triangulación metodológica, el trabajo se propone: a) analizar las tensiones entre los ideales de asociativismo propugnado desde las experiencias de ESS y las formas efectivas de proceder que se registran en los participantes de la misma; b) describir las formas de intervención estatal en las experiencias asociativas estudiadas, considerando específicamente fuentes y modalidades de asistencia técnica (financiamiento y capacitación).

Vinculado a dichos objetivos, las hipótesis de investigación son:

1. Las tensiones observadas entre el asociativismo propugnado en las experiencias analizadas (políticas públicas de ESS en San Martín) radica en el hecho de que el sujeto integrado a las mismas busca en estas iniciativas más un alivio y contención individual y temporaria a las dificultades de inserción socio-laboral que la consolidación de una forma alternativa de alcanzar la reproducción de la vida.

2. Las formas de intervención estatal en las experiencias asociativas condicionan de manera significativa el financiamiento y capacitación de las mismas, por lo que pueden pensarse como respuestas paliativas a los problemas de inserción socio-laboral de segmentos vulnerables de la población más que como iniciativas estatales tendientes a construir una cultura asociativa en dichos segmentos.

La investigación se desarrolla a partir de un enfoque de triangulación metodológica que recurre esencialmente a fuentes de información secundarias (documentos oficiales estadísticas y bibliografía académica) y primarias (entrevistas semi-estructuradas y observación directa, realizadas durante 2017).

El objeto de la investigación son las tensiones observadas en las experiencias analizadas. Para el caso de las políticas públicas en San Martín, cabe precisar que la elección se ha realizado considerando: a) vínculos entre experiencia asociativa y políticas públicas; b) antigüedad y alcance de dicha experiencia; y c) alcance y diversidad de sujetos sociales involucrados. El recorte temporal indagado es el lapso 2016-2017, el cual posibilita observar el devenir de las experiencias en contextos socio-económicos diferentes (post-convertibilidad, contexto de crisis mundial, finalización del ciclo neo-desarrollista y renovada irrupción del régimen de acumulación de valorización financiera). Cabe notar que si bien el recorte temporal se circunscribe al bienio citado, se recurre a información cuantitativa y cualitativa de años previos, útiles para contextualizar el objeto de la investigación. En relación al abordaje espacial, este se halla circunscripto al ámbito de interacción de las experiencias asociativas, fundamentalmente centrado en la escala local, aunque reconociendo desde la misma la interfaz regional y na- 
cional a partir de los vínculos que permiten las dimensiones de análisis inscriptas en las hipótesis de la investigación.

El trabajo se organiza en cinco apartados. Tras la introducción, se desarrolla un sucinto marco conceptual que se estructura en dos apartados: a) políticas públicas y agenda pública en la ESS y b) asociativismo, reciprocidad y solidaridad en la ESS. En el cuarto apartado, se explora el caso de San Martín. Por último, se presentan las reflexiones preliminares.

\section{Políticas públicas y agenda pública en la ESS}

En este apartado se exponen conceptos útiles para indagar la relación entre agenda pública, políticas públicas y ESS. Se trata de un vínculo circunstanciado en tiempo y espacio (la Argentina del lapso 2003-2017) en el que han proliferado y desarrollado demandas sociales centralmente ligadas con la problemática del empleo, incluyendo también reclamos por comercio justo, hábitat popular y espacio público.

Desde mediados de la década de 1990, con el agotamiento del Plan de Convertibilidad ${ }^{3}$ evidenciado en la creciente conflictividad social, se intensificaron formas de protesta en la vía pública. Puesto en dificultad el clásico vínculo patrón-obrero, los "piquetes — nombre habitual con el que se denomina al corte de vías de tránsito acompañado de una manifestaciónexpusieron las tensiones al interior del mundo del trabajo (CIOLLI, 2015: 10). En ese contexto, las estrategias de resistencia han ido redundando en un entramado de redes de solidaridad y contención que se plasmaron en el surgimiento de diversidad de organizaciones, movimientos sociales, centros comunitarios, mercados populares y espacios culturales, entre otros. La expresión institucional de agrupamiento de los mismos suelen ser los movimientos de trabajadores desempleados (Ibidem).

El escenario acaecido en las postrimerías de las Convertibilidad ha ido permeando en la agenda pública, aunque la misma ha podido consolidarse en la medida que también ocupó la agenda de gobierno. Considerando los aportes de COBB et. al. (1976: 128) se diferencia "agenda pública» de "agenda de gobierno». Con la primera se refiere a temas conocidos que: a) para una porción significativa del público requieren de acción, y b) son

3 Precisamente, se refiere a la caja de conversión peso argentino-dólar estadounidense mediante el establecimiento de una paridad fija que rigió la política monetaria del país entre abril de 1991 y diciembre de 2001. Las consecuencias socio-productivas más evidentes de esta política han sido el ingreso de capitales especulativos asociados a la fuga de divisas, la desestructuración del tejido industrial, el auge de importaciones, la primarización de las exportaciones y la destrucción masiva de empleos - y junto con ello las capacidades socio-laborales-. 
percibidos como cuestiones que son competencia de alguna unidad gubernamental. Por su parte, con agenda de gobierno se alude a la lista de temas considerada formalmente por quienes adoptan decisiones.

Desde la perspectiva planteada, las demandas sociales canalizadas a través de las experiencias de producción autogestionada y asociativa, surgen como fenómeno social en un contexto de impugnación popular de los mecanismos tradicionales de representación política-partidaria (Ciolli, 2015: 13-14). Por lo tanto, el vínculo entre actores sociales y burocracia puede comprenderse como dinámico y mutuamente influido. En esta dirección, Vaillancourt y Leclerc (2011) desarrollan las nociones de co-producción y de co-construcción de las políticas públicas. ${ }^{4}$ Con estos conceptos, los autores refieren a la participación: a) de los actores sociales y agentes económicos en la implementación de aquellas; y b) de los actores sociales en la definición o la elaboración de las políticas (identificación de sus fundamentos y orientaciones generales). Según los autores, estas prácticas conllevan formas de gobernanza basada en la participación de los actores de la sociedad civil y del mercado. En la definición o elaboración de politicas públicas, éstos se ligan con el Estado a través de los funcionarios que integran la burocracia. Desde la posición que así se asume, la burocracia resulta más que la suma de los intereses de sus integrantes. Aquí se alude a la burocracia en tanto capacidad - o incapacidad- de influir, lo que se torna dimensión explicativa de las distintas configuraciones que ella adquiere en la historia. ${ }^{5}$ Entonces, como institucionalización del estado en una organización social capitalista, OSZLAK (1977: 25) halla que la burocracia estatal cumpliría tres roles: a) sectorial, al asumir la representación de sus intereses propios como un actor más de la sociedad; b) «mediador, a través del cual expresa, agrega, neutraliza o promueve intereses, en beneficio de sectores económicamente dominantes; y c) infraestructural, proporcionando los conocimientos y energías necesarios para el cumplimiento de fines de interés general, habitualmente expresados en los objetivos formales del estado» (ibidem).

${ }^{4}$ En esta investigación se define a las políticas públicas como «el conjunto de actividades de las instituciones de gobierno, actuando directamente o a través de agentes, y que van dirigidas a tener una influencia determinada sobre la vida de los ciudadanos» (Ruiz López y Cádenas Ayala, 2004: 1). Éstas implican un «proceso decisional» (PALLARES, 1988: 143) establecido «alrededor del surgimiento, tratamiento y resolución de cuestiones socialmente problematizadas ante las cuales el Estado y otros actores toman posición» (Oszlak y O'Donnel, 1976:10).

5 OSZLAK (2006: 13) diferencia burocracia de estado, entiende que aquella es su expresión material. La noción de estado implica un orden legal con atributos (tributario, seguridad) que exceden el concepto de aparato institucional. 
Desde las nociones de co-producción y de co-construcción de Vaillancourt y Leclerc (2011) y considerando a Ciolli (2015: 14) la constitución de las cooperativas y emprendimientos asociativos autogestionados como sujetos de interpelación estatal a través de las políticas públicas puede entenderse como producto de un doble movimiento de transformaciones: a) en los modos de problematizar las demandas, conflictos y prácticas sociales que ha redundado en la apertura de un espacio para la innovación en el campo de las políticas sociales; b) en las particularidades socio-económicas de los actores sociales que integran las cooperativas de nuevo tipo, en las demandas que buscan satisfacer, en sus trayectorias laborales y en su vínculo con las instituciones estatales (pfr. Ibidem). Por lo tanto, resulta significativa la indagación en torno a las formas en que se desarrolla dicha interpelación estatal, así como la diversidad de tomas de posición que pueden registrarse desde las experiencias de ESS, a través de las cuales se observa la capacidad de decidir sobre sus propias condiciones económicas. A partir de las nociones co-producción y de co-construcción resulta posible comprender las formas de intervención pública en el mercado y en la sociedad civil, a través de las cuales indagar los dispositivos estatales construidos en interacción de la ESS y tendientes a incidir sobre actitudes, valores, disposiciones, proyectos y demandas de los integrantes de las cooperativas y emprendimientos asociativos autogestionados para avanzar en el desarrollo de procesos innovadores y democráticos.

En suma, las transformaciones en los modos de problematizar y en las particularidades socio-económicas han implicado novedosas formas de co-producción y de co-construcción. Por caso, en la primera mitad de la década de 2000 se modificó el lugar de la ESS en la agenda de gobierno; debido a que se registraron modificaciones en el organigrama estatal nacional. La institucionalidad regulatoria y de promoción ha ido centrándose en los ministerios nacionales de Desarrollo Social y de Trabajo, Empleo y Seguridad Social, así como en áreas específicas de organismos descentralizados (p.e., Instituto Nacional de Tecnología Industrial, Instituto Nacional de Tecnología Agropecuaria, Comisión Nacional de Microcréditos). Sin embargo, este vínculo entre co-producción, co-construcción e institucionalidad resulta particular de acuerdo al área que se indague y la articulación de hecho que se haya desarrollado entre funcionarios, actores sociales y agentes económicos.

Para finalizar, la particular articulación aludida entre agenda de gobierno, actores sociales y agentes económicos puede reconocerse en multiplicidad de trayectorias político-partidarias e identitarias que nutren la cosmovisión en torno a las nociones de asociativismo, reciprocidad y solidaridad en la ESS. Tras abordar esto último, se focalizará en dicha particularidad a través del estudio de las políticas públicas de ESS registradas en la Municipalidad de San Martín, Provincia de de Buenos Aires. 


\section{Asociativismo, reciprocidad y solidaridad en la ESS}

Las nociones de asociativismo, reciprocidad y solidaridad han sido objeto de profusos estudios (por caso, Coraggio, 2014 y Acevedo, 2010, entre otros). Usualmente se ha reconocido su potencial performativo, mientras sus alcances efectivos en las experiencias de ESS han sido una problemática relativamente menos explorada. Esta carencia se observa en un contexto estructurante en que la racionalidad capitalista occidental en su etapa neoliberal concibe y promueve una cultura en la que el trabajador llega a percibirse simultáneamente como empresario de sí mismo (Laval y Dardot, 2017; Merlin, 2015 y 2017; Alemán, 2016). En ese marco, las relaciones de poder entre trabajadores de la ESS se construyen a partir de la coexistencia contradictoria de sentimientos (solidaridad/ competencia) y prácticas — producción para el autoconsumo, al tiempo que se prioriza la producción orientada al mercado- (PRESTA, 2015: 204). Paradojalmente, el trabajador asociativo contemporáneo reproduce elementos propios de una economía del don al ceder voluntariamente el tiempo de trabajo, el don de sí y la naturalización de una relación constante (y hasta creciente) de deuda. En términos de PRESTA (2015: 202) el don de sí implica la entrega de afectos y pasiones dirigidos a un fin y a una actividad que los trasciende. En efecto, la construcción de "Otra Economía» resulta en las experiencias de ESS un horizonte ideal que implica al mismo tiempo una coexistencia contradictoria entre los imperativos de desenvolver la individualidad y desarrollar la solidaridad (ibidem: 203), entre la naturalización del cuentapropismo y la construcción de lazos de reciprocidad que trasciendan las relaciones mediadas por el mercado capitalista.

Al recurrir a Godelier (1996), se comprende que el don posibilita una aproximación entre los trabajadores asociados, debido a que se constituye en reparto aunque simultáneamente implica una separación, dado que cada quien es deudor del otro. Desde esta perspectiva, el don resulta un acto de generosidad y de desconfianza disfrazada de gesto desinteresado, debido a que se ejerce a través de y bajo la forma de reparto. Siguiendo a Godelier (1996), Vaillancourt y Leclerc (2011), Ciolli (2015: 14) y Presta (2015), al reconocer al don en tanto utopía puede considerarse su instrumentalización estatal a través del dispositivo de co-construcción de la ESS. Asimismo, en el contexto de las experiencias asociativas, el don puede entenderse como condición necesaria para enfrentar los contextos de crisis socio-laborales. Sin embargo, al mismo tiempo se recrea como un medio para la inserción en el mercado (Presta, 2015: 203).

La noción de solidaridad en la ESS también ha sido objeto de estudio en autores con enfoques diversos (Gaiger, 1999; De Melo Lisboa, 2004, 
entre otros). La propia noción ha adquirido distintos sentidos a lo largo del tiempo. De Melo Lisboa (2004) indaga en las definiciones brindadas por Durkheim, para quien puede observarse una solidaridad mecánica cuando se constituyen relaciones comunitarias (familiares, de vecindad) con códigos culturales determinados y naturalizados, en los que se privilegia el sentido de proximidad, protección y seguridad frente a riesgos y adversidades. Los procesos de modernización implicada en la expansión del capitalismo a diversas esferas sociales, han puesto en tensión las relaciones de proximidad para promover formas de solidaridad orgánica, en los que la ésta se circunscribe a la esfera privada y a la esfera pública (institucional y corporativa) habitualmente mediadas por el Estado. Por último, De Melo Lisboa (2004), identifica que la monetización como medio para la socialización implica una despersonalización de las relaciones para llegar a una socialización de-solidarizante en el que se disuelven lazos sociales. En ese proceso, los trabajadores se constituyen socialmente con otros quienes son extraños, en una cotidianeidad atravesada por el temor ante sus vulnerabilidades y por la naturalización de la desigualdad que quiebra con el sentimiento de igualitarismo entre los seres humanos. $\mathrm{Pa}-$ radójicamente, la individualización extrema proviene del tipo de sociabilidad contemporánea. No obstante, resulta incierta una liberación de la dependencia mutua que a la vez implica una autonomía del yo. Por lo tanto y desde este enfoque, la solidaridad posee un objetivo civilizatorio en el que pueden coexistir los principios de competencia y cooperación (De Melo Lisboa, 2004).

A la socialización de-solidarizante cabe agregar que la racionalidad neoliberal, impulsada ostensiblemente desde los enraizamientos que la misma ha detentado aún en contextos neo-desarrollistas incluso en las propias disposiciones estatales (ver Fernández, 2016), ha logrado agregar una ficticia igualación de los intereses de la(s) clase(s) trabajadora(s) producto de la fragmentación/heterogeneización social con los intereses de la(s) clase(s) propietaria(s). Esta ficticia igualación social se liga con la promoción de la imagen de la meritocracia y una extendida idea sobre la posibilidad de éxito en la transformación de la clase proletaria en clase "emprendedora», adiestrada por el coaching y la autoayuda (Merlin, 2017: 72).

En relación a las experiencias de ESS, la exploración de una plenitud de sentido se centra en la necesidad de vincularse con el mercado en tanto sujetos históricos, más como emprendedores que como trabajadores. Esta forma de emprendedurismo persigue la promesa de un trabajo emancipado de los requerimientos típicos del trabajo asalariado, por lo cual detenta un contenido de esperanza en el futuro. Las formas de regulación del mercado al que se ha aludido también precisan una regulación y autorregulación de la esperanza, en una creencia en la posibilidad efectiva de construir «Otra 
Economía», en modos de comprender y significar la relación con los sujetos, consigo mismos y con los demás (Presta, 2015: 204).

El aludido objetivo civilizatorio se logra mediante las regulaciones del mercado, entre ellas la competencia, mientras se apela la universalidad de la solidaridad (Presta, 2015: 204). No obstante, esta autora evalúa que las experiencias asociativas deberían partir por considerar la constitución histórica de los sujetos y sus condicionantes estructurales, puesto que ambas influyen sus prácticas, ancladas en un objetivo civilizatorio que implica la idealización de un deber-ser, la naturalización de modos de ser y hacer. En este sentido, la relevancia que adquiere la dimensión ética y moral incide en la naturalización del orden del mercado aunque paradójicamente discutiendo sus preceptos. Tal dimensión se nutre de elementos heterogéneos y hasta contradictorios (de raigambre cristiana, liberal, neoliberal, socialista cooperativa, autogestionario, etc.) resulta de central importancia para comprender el origen de las tensiones propias a los procesos de subjetivación reconocibles en las experiencias de ESS.

Por lo antedicho, en la literatura preocupada por indagar las iniciativas asociativas y su imbricación con las políticas públicas relacionadas, suele hacerse mención a las tensiones que sobrevienen a su implementación (por caso, ver Hopp, 2008). Sin embargo, el relevamiento bibliográfico efectuado ha resultado infructuoso a la hora de hallar aportes teórico-metodológicos que tornen operativa la categoría analítica "tensiones» en función de los objetivos trazados. A partir de los antecedentes hasta aquí expuestos, se postula una operacionalización de dicha categoría a partir de las siguientes dimensiones: a) motivaciones éticas (aspectos procedimentales socialmente considerados como coherentes y necesarios, lugar del autoconsumo y del excedente en la producción); b) capacidad de decisión y autonomía (márgenes operativos de definición sobre las iniciativas, tipo de vínculo con las políticas públicas que sustentan las iniciativas); c) solidaridad (mecanismos de regulación solidaria del trabajo vis a vis las formas de regulación de la competencia registradas en mercado, formas de accionar asociativo vis a vis emprendedurismo individual); d) nivel de concientización política ${ }^{6}$ (posicionamiento de los asociados frente al escenario económico en el que surgen y se reproducen). Estas dimensiones analíticas se plantean en dos niveles, el institucional y el de los sujetos.

${ }^{6}$ De acuerdo a Freire (pfr. 1974), la concientización es un proceso de acción cultural a través del cual los individuos despiertan a la realidad de su situación sociocultural, avanzan más allá de las limitaciones y alienaciones a las que están sometidos. En este proceso, se afirman a sí mismos como sujetos concientes y co-creadores de su futuro histórico. 


\section{La experiencia del Municipio de San Martín}

El Municipio de Gral. San Martín se encuentra ubicado al noroeste del Área Metropolitana de Buenos Aires - AMBA-, lindero a la Capital Federal. Se trata de uno de los distritos de mayor densidad poblacional en la Provincia de Buenos Aires $\left(7.550 \mathrm{hab} / \mathrm{km}^{2}\right)$ y también de los más poblados — 431.854 habitantes de acuerdo al censo de INDEC - (2010).

El Municipio detenta algunas particularidades económicas y socioambientales. Según el Censo Nacional Económico 2004-2005 (INDEC, 2005) es uno de los partidos de mayor industrialización del AMBA: la cantidad de locales industriales ocupa el 5,4\% de la superficie municipal. Como contrapartida, esta magnitud se halla significativamente afectada por crisis económicas que reducen temporalmente el salario real. En el contexto actual (post-2015) el incremento de los costos fijos y variables, sumado a la caída del consumo — producto de la caída del salario real—, genera dificultades serias en el sostenimiento de los entramados productivos y dificultades significativas para generar y mantener el empleo industrial y de servicios asociados.

\section{Cuadro 1}

Municipio de General San Martín (Provincia de Buenos Aires, Argentina)

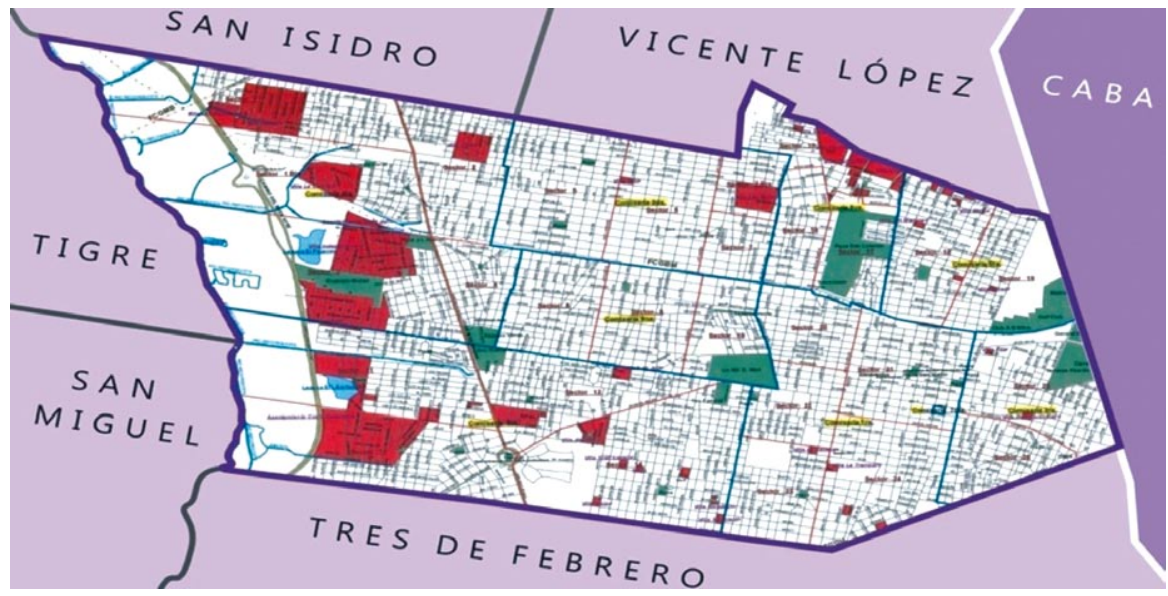

Fuente: Municipalidad de San Martín (2017).

Asimismo, una particularidad socio-ambiental de este municipio consiste en el marcado contraste social entre diferentes estratos sociales. Por un lado, las áreas de mayor poder adquisitivo se ubican en la zona centro y lin- 
dera a la Capital Federal. En contraposición, la zona norte del municipio lindera a las cuencas de los ríos Reconquista y Medrano alberga a aproximadamente 164 asentamientos o villas miseria. Aproximadamente un tercio de la población — 150 mil personas - residen en José León Suárez (entre la cuenca del Río Reconquista y la Avenida Márquez — representada en color rojo en el tercio izquierdo del mapa-).

Estas particularidades motivaron a la actual gestión municipal (Intendencia de Gabriel Katopodis, iniciada en 2011 y reelegida en 2015) a desarrollar políticas públicas diferenciadas. Desde la misma, se ha propugnado una perspectiva integral que atendiera tanto el desarrollo productivo local como la generación de oportunidades para la reproducción social de una población históricamente postergada. En este esquema de gestión, la Dirección General de Economía Social y Solidaria, bajo la órbita de la Secretaría de Desarrollo Social del Municipio ha cobrado un rol significativo a la hora de ligar demandas insatisfechas por el mercado (fundamentalmente, inserción en el mundo del trabajo) con la generación de instrumentos de intervención.

En términos esquemáticos, puede observarse que la inversión social y laboral destinada a sectores vulnerables en el contexto del presupuesto municipal ha oscilado en la presente década entre 5 y cerca de $13 \%$ del mismo.

\begin{tabular}{ccccc}
\hline Ejercicio & $\begin{array}{c}\text { Secretaría de } \\
\text { Desarrollo Social (1) } \\
\text { (en millones de } \\
\text { AR\$) } \\
(\text { en millones de } \text { ) })\end{array}$ & $\begin{array}{c}\text { Agencia Promoción } \\
\text { de Empleo } \\
\text { Capacitación } \\
\text { Laboral (2) }\end{array}$ & $\begin{array}{c}\text { Total (3) (en } \\
\text { millones de AR\$) } \\
\text { (en millones de } €)\end{array}$ & $\begin{array}{c}\text { Participación } \\
(1+2 / 3) \\
(\text { en millones) }\end{array}$ \\
\hline 2011 & $51(8,5)$ & $587(97,8)$ & 8,6 \\
2012 & $73(12,6)$ & $1.471(253,6)$ & 5,0 \\
2013 & $100(14,1)$ & $1.227(172,8)$ & 8,1 \\
2014 & $136(12,0)$ & $1.530(135,4)$ & 8,9 \\
2015 & $141(13,2)$ & $159(9,0)$ & $2.697(154,1)$ & 12,8 \\
2016 & $185(10,6)$ & $13(0,7)$ & $3.903(195,2)$ & 6,9 \\
2017 & $255(12,8)$ & & $2.036(190,3)$ & 6,9 \\
\hline
\end{tabular}

Fuente: elaboración propia en base a Municipalidad de San Martín (2018).

Nota: para el cálculo del tipo de cambio AR \$-€ se han tomado los valores del tipo de cambio del primer día hábil del mes de julio de cada año, según el Banco de la Nación Argentina. 
De acuerdo a sus responsables técnicos, la finalidad de la Dirección General de Economía Social y Solidaria radica en diseñar instrumentos integrales que contemplen al sujeto en tanto agente económico con derechos (Entrevista personal , 10-4; 18-5 y 19-12/2017). Por lo tanto, el objetivo de la intervención persigue la generación de empleo y la reproducción social de las familias. Operativamente, se busca integrar a los sujetos sociales como actores participantes del diseño y ejecución de las políticas públicas. Esta matriz de diseńo participativo y en consonancia con lo definido como "co-construcción» o "coparticipación» en el vínculo entre actores sociales y burocracia (Vaillancourt y Leclerc, 2014), abreva en el devenir histórico reciente. Se trata de una trayectoria que resulta posible rastrear desde fines de la década de 1990, en los aprendizajes de la ejecución de instrumentos estatales dirigidos a atender la problemática socio-laboral como un elemento emergente.

En el esquema planteado, se pretende integrar a los productores también como consumidores en vistas a articular la cadena productiva a través de una comercialización sostenida. Se trata de herramientas de apoyo y fomento diseñadas que se dirigen a fines específicos (producción, comercialización, financiamiento y capacitación) a través de las cuales se pretende transformar el modo de interpelación estatal de las particularidades socioeconómicas de la población (Ciolli, 2015).

La población destinataria de los diferentes instrumentos son tanto unidades domésticas con trabajo autogestionado, como grupos asociativos integrados a partir de diferentes formas jurídicas. Entre ellas, predominan las cooperativas de trabajo y principalmente fábricas recuperadas que irrumpieron fundamentalmente a través de procesos de autogestión obrera como consecuencia de la de la crisis socioeconómica de 2001/2002.

Desde 2015, la gestión de ESS municipal: a) dicta 62 cursos paralelos en más de 30 centros de formación en oficio localizados principalmente en el barrio de José León Suárez, de los que participaron cerca de 3.000 asistentes; b) desarrolla un curso de gestión de emprendimientos con sede en la incubadora municipal de empresas de Economía Social (actualmente denominada "San Martín Emprende») donde a través de módulos de 8 clases de 4 horas cada una se abordan los diferentes procesos de gestión: productivos, administrativos, económico financieros, de comercialización, etc. Ambas iniciativas se conciben como forma de tensionar la lógica individualista del emprendedurismo característico de la década de 1990. El enfoque asumido por la gestión municipal propone trascender la capacitación enfocada en la competencia laboral y recupe$\mathrm{rar} /$ construir formas de solidaridad donde se complementen saberes, experiencias y oportunidades. 
En particular, en la gestión de la Dirección General de Economía Social y Solidaria de la Municipalidad de San Martín:

1. En «San Martín Emprende», se busca atender las demandas de experiencias asociativas que presentan dificultades en el inicio de las actividades y fragilidades en aspectos de organización productiva. Desde este instrumento, se brinda asesoramiento y tutorías periódicas, así como la posibilidad de trabajar en espacios comunes haciendo uso de herramientas e instalaciones brindadas por la incubadora municipal de empresas de Economía Social.

2. El «Programa Fábrica de Oportunidades» ubicado en el Polo Comunitario Savio, en donde la gestión brinda los recursos en carpintería, herrería, serigrafía, estampados, huertas etc. Asimismo, el "Centro de Oportunidades para la Inclusión», nuclea cerca de 200 jóvenes con discapacidades que pueden encontrar oportunidades para su inserción laboral y capacitaciones específicas. ${ }^{7}$

3. El «Fondo de Financiamiento Solidario» (FFS), en donde se financia a los trabajadores autogestivos y a las cooperativas de trabajo a través de esquemas de microcréditos. El fondo de financiamiento dispone de dos líneas específicas. Por un lado, el acompañamiento a proyectos productivos y de servicios, y por otro una línea específica de mejoramiento habitacional, en donde se financian pequeńas obras, regulación dominial y conexiones a servicios públicos. La particularidad de ambas líneas radica en que buscan trascender una transferencia económica, puesto que contemplan al sujeto de crédito en sus particularidades y entendiendo la dinámica propia del sector de la ESS. En este sentido, se pretende que el microcrédito recibido se transforme en una herramienta formativa para poder consolidar el proceso productivo logrando la sustentabilidad temporal necesaria para proyectarse. Para ello, se diseñan esquemas de capacitación específicos y obligatorios previos a obtener los fondos, sumado al acompańamiento a los trabajadores asociados por parte de los técnicos intervinientes durante la ejecución del crédito. En este caso, se observa una tutoría de hecho que pretende brindar herramientas adecuadas para el sector y posibilidades de comercialización y articulación con otros actores.

4. En el contexto de demandas sociales referidas al consumo responsable, la Dirección General diseña distintos esquemas de comer-

7 Además, el polo alberga la "Casa Abrigo» en donde 150 personas en situación de calle pueden pasar la noche y recibir durante el día atención sobre sus necesidades con equipos capacitados para ello. 
cialización que buscan la reducción/eliminación de la intermediación. Por un lado, las «Tiendas Solidarias» consisten en espacios de comercialización asociativa entre productores, consumidores y Municipio. Enmarcados en alguno de los programas precitados, los primeros pueden disponer de los espacios para la venta directa al público. Como contrapartida, se busca la participación asociativa del proceso de comercialización y organización de los tiempos y los espacios. Por ende, cada productor se compromete a brindar parte de su tiempo para comercializar los productos de todos los que forman parte. Por otro lado, el programa «Manos de San Martín» funciona desde 2011 y nuclea nueve ferias mensuales en el partido distribuidas en diferentes días y espacios rotativos. En diciembre de 2017 contaba con cerca de 200 emprendimientos activos. La premisa de organización se centra en el vínculo directo entre el productor y el consumidor. El espacio se halla cogestionado entre los referentes de la Dirección General y los mismos feriantes, quienes para participar asumen la responsabilidad del trabajo conjunto definiendo: a) variedad de productos ofrecidos, b) condiciones y precios de ventas, c) administración de los puestos y cobro de cada stand, d) diseño y estética de la Feria, etc. Por su parte, el municipio ofrece los recursos necesarios, la logística de traslados, el armado de los puestos y de los espacios para la administración.

En los encuentros a los que se ha asistido, se ha constatado el desarrollo de una fidelización entre feriantes y consumidores (Entrevista personal, 10-4, 18-5 y 19-12-2017). Asimismo, los propios feriantes han logrado una organización de la producción entre las distintos espacios de comercialización a fines de alcanzar acuerdos de precios, diversidad y calidad de los distintos bienes comercializados, esquemas de distribución del mercado (a los fines de evitar un solapamiento de la oferta) y logística de administración (cobro por alquiler de puesto).

Detrás de esta organización de feriantes suele subyacer la idea de sostener los valores solidarios que implican la asociación de los puesteros, que trascienden su lugar como sujetos individuales y buscan erigirse como un colectivo de productores asociados. Más allá de la concepción desde la que se sostiene la experiencia, cabe señalar vínculos contradictorios entre la dirigencia asociativa y feriantes. Desde la perspectiva aquí asumida, los desiguales niveles de concientización política implican que la primera pueda asumir de hecho una lógica de vanguardia, en el que las relaciones suelen verticalizarse. Desde esta forma de accionar, resultan verificables tensiones en cuanto a lo pretendido desde la Institución municipal y sus principales dirigentes, lo que efectivamente ocurre en el territorio cuando son los 
mismos sujetos lo que se conciben proyectivamente. A partir de PRESTA (2015), se observa una coexistencia contradictoria entre sentimientos de solidaridad y de competencia en cuanto a las prácticas productivas

La búsqueda de esquemas emancipatorios ${ }^{8}$ en cuanto a la autonomía en el sostenimiento de los procesos asociativos encuentra limitantes según diferentes momentos de concientización del rol político social que espacios como «Manos de San Martín» detenta. De los más de 200 feriantes que participan del espacio, un porcentaje importante no logra visualizar la oportunidad de apropiación de las herramientas puestas a disposición, exigiendo al Municipio respuestas de carácter individual y comercial de corto plazo, en lo que PRESTA define como la contradicción entre los imperativos de desenvolver la individualidad y de desarrollar la solidaridad.

En suma, puede identificarse una marcada dependencia de los productores asociados a los dispositivos del Municipio. Esta dependencia impide una efectiva emancipación, aspecto que se desenvuelve en forma estructural debido a que sin espacios de comercialización y de financiamiento público, difícilmente podrían sostenerse los emprendimientos en el tiempo. Ocasionalmente, ello puede observarse cuando las ferias se suspenden por cuestiones climáticas. En situaciones como las aludidas, no se procuran alternativas de realización en espacios propios de comercialización, aspecto que perjudica considerablemente la economía familiar de los feriantes al interrumpirse el flujo de ingresos a la vez que restringe las posibilidades de los clientes de adquirir productos a precios justos. Un indicador que evidencia ello es la posibilidad efectiva de cumplimiento con las obligaciones asumidas frente al Fondo de Financiamiento Solidario. En efecto, la complementariedad de herramientas que buscan el fortalecimiento de los emprendimientos y su emancipación político-económica se halla condicionada cuando uno de los elementos entra en tensión. Si la comercialización en las Ferias se reduce, éstas no logran obtener financiamiento municipal. Esto implica una espiral descendente, en donde los mismos dispositivos atentan contra el sostenimiento de los emprendimientos.

Por último, la socialización de-solidarizante en la que priman la alienación típica del fordismo y su sociedad salarial, se constituye en un tópico recurrente por parte de los participantes de las políticas públicas locales de ESS. La alusión a los ritmos y condiciones del trabajo típicos del empleo registrado y monetizado, puede desestimar la cotidianeidad atravesada por el temor ante sus vulnerabilidades y la naturalización de la desigualdad. Ese

8 Por esquemas emancipatorios aquí se asume la definición de Habermas (1982) relativa a la búsqueda de dimensiones alternativas de racionalidad comunicativa. Es decir, una posición crítica que a través de enfoques participativos, conduzca a una toma de conciencia liberadora y ética, haciendo eje en las relaciones de poder. 
lugar común que recurre a pasados presuntamente idílicos desestimando que la individualización extrema proviene del tipo de sociabilidad contemporánea. En este contexto, la solidaridad como objetivo civilizatorio (De melo Lisboa, 2004) difícilmente pueda realizarse ante la exacerbación de formas de competencia típicas de la sociedad del rendimiento (Laval y Dardot, 2017) en la que dichas formas tienden a desplazar el principio de cooperación.

\section{Reflexiones finales}

Esta investigación ha pretendido avanzar en el análisis de las tensiones entre los ideales de asociativismo propugnado desde las experiencias de ESS y las formas de proceder que se registran en los participantes de la misma así como en la descripción de las formas de intervención estatal en las experiencias asociativas seleccionadas.

La imbricación analizada entre políticas públicas de San Martín y ESS dista de ser un ámbito armónico y de implementaciones coherentes. En las experiencias aquí aludidas, se percibe una conjunción de formas de intervención provenientes de inspiración neoliberal (emprendedurismo) junto con una voluntad institucional de construir vínculos horizontales con los sujetos sociales participantes de iniciativas enmarcadas en San Martín Emprende. En el contexto de impulso al asociativismo desde la Dirección General de Economía Social y Solidaria municipal, puede evidenciarse la tensión que implica una marcada dependencia de los asociados a dispositivos del financiamiento estatal (capacitación y logística en el caso de San Martín, subsidio a los costos, entre otros). Esta dependencia impide un efectivo esquema emancipatorio en los términos de Habermas (1982), aspecto que se vuelve estructural debido a la carencia de espacios alternativos y/o específicos de comercialización y de financiamiento.

En segundo término, cabe interrogarse en torno a la primera hipótesis. Las iniciativas analizadas pueden entenderse como un alivio y contención individual y temporaria a las dificultades de inserción socio-laboral, antes que una forma alternativa de alcanzar la reproducción de la vida. Esto sucedería debido a que las experiencias no han redundado en procesos de construcción de formas de solidaridad que trasciendan el propio impulso y sostenimiento estatal de tipo coyuntural. Incluso, se trata de un vínculo social que aspira a la contención y que se evidencia en el hecho de iniciativas estatales co-construidas a partir de márgenes operativos estrechos, financiamientos acotados y en esquemas próximos a un paternalismo estatal dirigidos a morigerar los conflictos capital-trabajo que atraviesan particularmente los sujetos sociales en sectores vulnerables de áreas industriales que 
padecen una crisis económica producida por políticas económicas neoclásicas.

En el marco arriba señalado, el binomio autonomía del yo-cooperación pareciera expresar una de las principales tensiones identificadas en escenarios marcados por la demanda de inmediatez en la resolución de problemas de inserción socio-laboral por parte de sujetos sociales que atraviesan contextos de vulnerabilidad. Paradójicamente, se trataría de una demanda de inmediatez en la que resulta incierta la construcción de un ámbito propicio para fomentar el desarrollo de prácticas asociativas que trasciendan la inmediatez y la propia resolución de problemas (generación de empleo, construcción de canales de comercialización para la producción local, acceso a alimentos a precio asequible, etc.), tras la cual el vínculo social sigue edificándose entre individuos atomizados y políticas públicas focalizadas.

Por último y en relación a la segunda hipótesis que ha guiado esta investigación, cabe plantearse que los condicionamientos estatales relativos al financiamiento y capacitación en las experiencias asociativas intervienen como dispositivos potenciadores (incluso posiblemente tendientes a la construcción de concientización política) y simultáneamente como reguladores de los procesos asociativos. En este marco, es cuando surge un nuevo interrogante para futuros estudios en las que se aborden las burocracias en el marco específico y cambiante de las agendas de gobierno y en sus roles sectorial, mediador e infraestructural.

\section{Bibliografía}

Acevedo, S. (2010): Representaciones sociales sobre asociativismo en procesos socioproductivos: el caso del proyecto hierbas, Santa Ana, Misiones. VI Jornadas de Sociología de la UNLP. Universidad Nacional de La Plata. Facultad de Humanidades y Ciencias de la Educación. Departamento de Sociología, La Plata.

Alemán, J. (2016): Horizontes neoliberales en la subjetividad. Grama Ediciones, Buenos Aires.

Ciolli, V. (2015): La economía social como herramienta de política estatal: un abordaje desde el Plan Manos a la Obra (Argentina 2003-2009), Consejo Latinoamericano de Ciencias Sociales, Buenos Aires.

Coraggio, J.L. (2014): «Una lectura de Polanyi desde la economía social y solidaria en América Latina», Cadernos Metrópole, São Paulo, v. 16, n. 31, pp. 17-35.

Cobb, R., Ross, J.K., y Ross, M.H. (1976): «Agenda building as a comparative political process», The American Political Science Review, v. 70, n. 1, pp. 126-138. 
De Melo Lisboa, A. (2004): Solidaridad, en Cattani, A.D. (org.) La otra economía. Altamira, Buenos Aires. pp. 389-401.

Fernández, V.R. (2016): «Desde el laboratorio neo-desarrollista a la resurgencia neoliberal: una revisión creative del 'doble movimiento' polanyano en América Latina», Revista Estado y Políticas Públicas, n. 7, pp. 21-47.

Freire, P. (1974): «Conscientization», Cross Currents, v. 24, n.1, pp. 23-28.

Godelier, M. (1996): El enigma del Don. Paidós, Madrid.

Habermas, J. (1982): Conocimiento e interés. Ediciones Taurus, Madrid.

Hopp, M. (2008): Tensiones en la construcción de la Economía Social como política social: la experiencia del Plan Nacional Manos a la Obra. V Jornadas de Sociología de la UNLP. Universidad Nacional de La Plata. Facultad de Humanidades y Ciencias de la Educación. Departamento de Sociología, La Plata.

Laval, C. y Dardot, P. (2017): La pesadilla que no acaba nunca, Editorial Gedisa, Barcelona.

Merlin, N. (2015): Populismo y psicoanálisis, Letra Viva, Buenos Aires.

Merlin, N. (2017): Colonización de la subjetividad. Medios masivos de comunicación en la época del biomercado, Letra Viva, Buenos Aires.

Municipalidad de San Martín (2017): Dirección General de Economía Social y Solidaria. Disponible en: http://www.sanmartin.gov.ar/institucional/secretariade-desarrollo-social/

Municipalidad de San Martín (2018): Cálculo de recursos y presupuestos de gastos. Disponible en: http:/www.sanmartin.gov.ar/transparencia/presupuestos/

INDEC (2005): Censo Nacional Económico 2004-2005, Buenos Aires.

INDEC (2010): Censo Nacional de Población, Hogares y Viviendas 2010, Buenos Aires.

Oszlak, O. y O’Donnell, G. (1976): Estado y políticas estatales en América Latina hacia una estrategia de investigación, Centro de Estudios de Estado y Sociedad, Buenos Aires.

Presta, S. (2015): «Solidaridad y formas de construcción de poder en el dispositivo de la economía social y solidaria Consideraciones en relación a un análisis de caso", Revista Cátedra Paralela, n. 12, pp. 193-215.

Vaillancourt, Y. y Leclerc, P. (2011): «La economía social en la co-producción y la co-construcción de las políticas públicas», Revista del Centro de Estudios de Sociología del Trabajo, n. 3, p. 1-38. 